DOI: 10.19085/journal.sijmas021003

\title{
Level of jealousy and marital adjustment amongst rural and urban working and non working couples
}

\author{
Samridhi Kanwar ${ }^{1}$ Roshan Lal Zinta ${ }^{2}$ Anurag Sharma ${ }^{3}$ \\ ${ }^{1}$ Researcher Scholar, Department of Psychology, Himachal Pradesh University, Shimla. \\ ${ }^{2}$ Associate Professor, Department of Psychology, Himachal Pradesh University, Shimla. \\ ${ }^{3}$ Associate Professor, Department of Geography, Himachal Pradesh University, Shimla.
}

OScholedge International Journal of Multidisciplinary \& Allied Studies (ISSN 2394-336X), Vol.02, Issue 10 (2015) p11-37. Published by: Scholedge R\&D Center [www.theSCHOLEDGE.org] [Email: sijmas@scholedge.org]

\begin{abstract}
Jealousy, the shadow of love and green eyed-monster that on the one hand has ruined marital homeostasis of millions of couples by creating fraction amongst the families and on the other also seems equally beneficial for promoting their La Dolce Vita philosophy of happiness across the world. It seems that foremost source of this covetous issue might be the insecurity and fear of being abandoned by one of the cherished partner due to extra marital relationship. The reason behind such apprehension might be the excessive flow of money, poverty that push away the people to leave sedentary mode of life and to adopt nomadic way, mismatch of thoughts, emotions and behavior, values of life, over involvement, much or less care, violation of customary practices, eating and sleeping habits, pro-social attitude, less mindfulness and more money mindedness; selfishness, performing job and business outside the native place. Such issues may results jealous by hampering their marital relationship in general and personal development in particular. Once a time when there use to be a faith and sacred relationship in marriage in India, that in contemporary Kaliyug scenario has diluted and faded away by converting into suspiciousness and jealousy. The level of jealous may differ among the working and non-working people in general and the rural and urban men and women in both developed and developing countries in particular as well as in hilly areas like Himachal Pradesh where the people are very honest now has followed the path of astuteness that in turn has disturbed their marital homeostasis. In the present study a pioneer attempt has been made to explore the relationship between jealousy and marital adjustment among 200 Working and Non-Working Couples of Rural and Urban areas of Himachal Pradesh. Based on locality and gender, 8 groups namely Urban Working Men, Urban Non-Working Men; Urban Working Women; Urban Non-Working Women; Rural Working Men, Rural Non-Working Men; Rural Working Women; and Rural Non-Working Women with $\mathrm{n}=25$ subjects in each have been formed. These subjects were assessed with the help of Multidimensional Jealousy Scale as developed by Susan M. Peiffer and Paul T.P. Wong in 1989's with seven point scale where the score ranged from minimum of 8 to maximum of 56 with the reliability of $r=.83$ to $r=.92$ respectively. The marital adjustment was measured with the Revised Dyadic Adjustment Scale as developed by Busby, Christensen, and Larson in 1995 that has 14 items with five and six point scale with a minimum score of 0 and maximum of 69 and reliability of $r=0.90$ respectively. The result revealed that Men reported well adjusted marital life but were more in Jealousy as compared to their Women counterparts. The Non-Working Men enjoyed
\end{abstract}


satisfied life thereof were well adjusted despite being reporting more Jealous as compared to Non-working Women counterpart. In the same tune, the Urban people reported better adjusted marital life but more jealousy than to the people of Rural area. For promoting better marital life there is need to reduce jealousy, promoting faith, self-esteem, mindfulness, self-esteem, confidence and vision by following honesty and yogic way of life amongst the men who seems to suffer from aforesaid issues.

\section{Introduction}

Jealousy, "the shadow of the love" is considered as the "green eyed-monster" that seems to have presented in this universe since the evolution of human being. According to the Panspermia hypothesis, microscopic life on the universe seems to be distributed by meteoroids, asteroids and other small solar system bodies existed on it and the possibility of life remained only on the earth where the bounty of supernatural power might have blossomed the love and example is Adam and Eve. According to Karl Marx love between man and woman is the immediate relationship of human being to the Supreme Being. In the words of Ahdat Soueif, an Arab novelist "Hubb" is love, "Ishq" entwines together, "Shaghaf nests the heart, "Hayam" wanders on the earth, "Teeh" lose yourself, "Walah" carries sorrow, "Sababah exudes from pores, "Hawa" shares its name with "Air" and with "Falling", and the "Gharm" is willing to pay any price. The passionate love is universal whereas the companion love is non-universal. The obsessive love represent infatuation "lovesickness and "being-inlove" embodied by a powerful emotional state. Similarly, the reciprocated love is associated with the fulfillment and ecstasy whereas unrequited love causes separation and is associated with feelings of emptiness, anxiety, and despair. The companionate love involves diminish potent feelings of attachment, an authentic and enduring bond, a sense of mutual commitment, the profound feeling of mutual caring, proud of a mate's accomplishment, and the satisfaction that comes from sharing goals and perspective. It is thought to be a "cooler" emotion that combines the feelings of deep attachment, commitment, and intimacy. It is a turbulent emotional state, with close links to joy, and happiness in general as well as the depression, sadness, fear, anger, and jealousy in particular. It is a complex functional whole that may include appraisals or appreciations, subjective feelings, expressions, patterned physiological processes, action tendencies and instrumental behaviors. On the other hand, the unrequited love (separation) is associated with emptiness, anxiety, or despair (Hatfield \& Rapson, 1993; Hatfield, 2008). The aforesaid love is a royal road to marriage on the one hand and jealousy and marital distress on the other that may prove sweet and sour in marital relationship in every strata of population across the world.

More appropriately, the love embodied a complex functional whole that may include an appraisal or appreciations, subjective feelings, expressions, patterned physiological processes, action tendencies and instrumental behaviors. If a person fails in such behavior, it may give rise the jealousy in which there are extreme love towards the person and one of the member is quite dominative. It seems that the foremost source of covetous issue of jealous might be the insecurity and fear of being abandoned by one of the close partner due to extra marital relationship, excessive flow of money, poverty that might push away the people to leave sedentary mode of life and to adopt nomadic way, mismatch of thoughts, 
emotions and behavior and values of life, over involvement, much or less care, violation of customary practices, eating habits, pro-social attitude, less mindfulness and more money mindedness; selfishness, performing job and business outside the native place may results in jealous that may hamper their marital relationship in general and personal development in particular.

Once a time when there use to be a faith and sacred or extreme cared and love relationship in marriage in India, that in contemporary Kaliyug scenario has faded by converting into suspiciousness and jealousy. Sant Kabir told that foolish people cannot discriminate between good and evil. Such men cannot be happy because the load of evil gets too heavy for them. According to Buddhist literature disturbing emotion are considered as Klesha deals with greed, attachment, hostility, anger, focuses on other peoples accomplishment, good qualities, possessions and success due to excessive attachment to their own gain. In jealousy there is more self-love than love.A ccording to Hinduism, it is by Gods law of karma that we go through guilt, transgressions, sorrow, hurting ourselves and others. The nature of the world is duality. It contains each thing and its opposite: joy and sorrow, goodness and evil, love and hate. Unlike many faiths, Hinduism admits of no mortal sin, no eternal hell, no satan, no intrinsic evil. According to Bible Jealousy is the uneasiness felt due to suspicion, resentment or fear of rivalry. Jealousy is basically, fundamentally, a spiritual problem. It is "hostility toward someone believed to enjoy an advantage. In the literature of Garudpurana it may rise when one of the partner treat their spouses well when they are to profit or pleasure to them. According to Shiv Purana and and Bhagvad Purana, it is Moha and Maya that result in hostility and jealousy. Men who have intercourse and cheat women with no intention of marrying them are considered like animals they are well of hell. Famous poet Kalidas warn again the negative emotions like anger, jealousy, greed, conceit, fault- finding etc.

Jealousy is one of those unnecessary evils we burden ourselves with. None of us could honestly say that we have not ever been jealous of more fortunate ones. Ironically, however, jealousy is generally found among equals or near equals like friends of equal social status, colleagues in the office and relatives. We are not jealous of someone who is either too highly placed or too distantly connected with us. Jealousy keeps us under a sense of discouraging frustration and disappointment. It makes us gloomy. It is such a depressing feeling that we cannot tell about it to even our best friends nor can we contain it within ourselves. Consequently, it leaves us with an inconvenience of a peculiar misery and if allowed to grow unchecked beyond a limit, it works like a slow poison to our healthy nature.

The level of jealous may differ among the working and non-working people in general and the rural and urban men and women both in educated and non-educated people both in developed and developing countries as well as in the people of hilly areas like Himachal Pradesh where the honesty was in their blood now has converted into astuteness by following scientific and technological path of development and advancement perhaps has disturbed their marital homeostasis. Social psychologists have found that secure persons have the most positive experiences in love. For the clingy, skittish, and fickle, passionate love can be stressful and lead to problematic relationships. The consequences of passion 
also depend, in part, on whether or not the passionate feelings are reciprocated. Those who are clingy are most vulnerable to "neurotic love" and have low self-esteem and ambivalent feelings. When a relationship is strong and intimate, a receiver perceives the communicator as credible and trustworthy and thus is more likely to follow the recommendation of opposite partner. When reciprocated, passionate love has been found to be associated with satisfaction and happiness, and to have a beneficial effect on the immune system. However, the stress resulting from unrequited love seems to be hazardous to mental and physical health (Hatfield \& Rapson, 1996). At the same time it has its numerous benefits.

The social commentators contended that the idealization of romantic and passionate love was a peculiarly in Western institution. Thus, cultural researchers began to investigate the impact of culture on people's definitions of love, what they desired in romantic partners, their likelihood of falling in love, the intensity of their passion, and their willingness to acquiesce in arranged marriages versus insisting on marrying for love. When social psychologists explored folk conceptions of love in a variety of cultures-including the People's Republic of China, Indonesia, Micronesia, Palau, and Turkey-they were surprised to find that men and women in all these cultures possessed surprisingly similar views of romantic love and other "feelings of the heart" (Jankowiak, 1995; Shaver, Murdaya \& Fraley, 2001). In love, there is a romance, whose dimensions according to social psychologists are the tales of idealized romantic love between two lovers; a dreamy, imaginative, cognitive state in which people imagine a perfect love relationship; and the feeling of romantic or passionate love.

In the early 1950, social psychologists focused on romantic love, attempting to discover if couple's attitudes toward romantic love had an impact on marital happiness and stability. People in all cultures recognize the power of romantic love. Be it a plain or hilly area both in developed and developing countries the people enmeshes in it. For example in hilly areas like Kinnaur of Himachal Pradesh there are various marital sacrament and the people even before marriage are involved in this romantic relationship. Not only this the people after marriage may become polyandrous and one wife is shared amongst the two or three real brothers (Zinta \&Negi, 2013; Negi \& Zinta, 2013). The romantic relationships were said to fall into one of four types: The secure relationship involve comfortable and independence the clingy; are comfortable with closeness but fearful of too much independence; the skittish are fearful of too much closeness but comfortable with independence; and the fickle as independence. Those who were relatively uninterested in relationships were said to fall into one of two categories namely the casual (who are interested in relationships only if they are almost problem free) and the uninterested (who are not at all interested in relationships, problem free or not). A perfect love therefore produces perfect citizen with balanced personality.

Social psychologists have charted the process by which infants, teenagers, and young adults learn to love and to balance the conflicting desires for closeness and independence. Pioneering scientists such as Ainsworth (1989), Bowlby (1979), and Freud (1922) have visualized the aid the way infants come to be attached to their caretakers. Erickson (1982) has deliberated the way the adolescents and young adults learn to negotiate the delicate 
balance between independence and interdependence. This attachment is based, they contended, on the necessity of caretakers-infant bonding, if young primates were to survive in the wild. Several researchers have demonstrated that both children and adults are especially prone to seek romantic ties when they are anxious and under stress. In a duo of studies, Hatfield and her colleagues for example found that children and teen-agers that were either momentarily or habitually anxious were especially vulnerable to passionate love.

Primatologists, such as Rosenblum and Harlow have pointed out that many primates, such as Pigtail Macaques, seem to experience a primitive form of passionate love. Recently, social psychologists, neuro-scientists, and physiologists have begun to explore the links between romantic and passionate love, sexual desire, and sexual behavior. Neurologists discovered that passionate love produce increased activity in the brain areas associated with euphoria and reward, and decreased levels of activity in the areas associated with distress and depression. Passionate love and sexual arousal appeared to be tightly linked. Other psychologists who have studied the links between passionate love and sexual desire have found similar results (Fisher, 2004.) Scientists interested in the chemistry of passionate love, sexual desire, and mating have found that a variety of neuro-chemicals changes are found it them (Carter, 1998; Marazziti \& Canale, 2004.) According to Fisher (2004) the passionate love, lust, and attachment are associated with slightly different chemical reactionsalthough generally coming together in a single package, thus is considered as natural stimulant. Lust is primarily associated with the hormone testosterone. Attachment is produced primarily by the hormones oxytocin and vasopressin. Researchers have found that men and women, who are casual about relationships, are less likely to have experienced either Passionate Love or Companionate Love than to their peers. Not surprisingly, those who are uninterested in relationships are extremely unlikely to have experienced such love. When individuals are in love, they are generally convinced that their passionate feelings will last forever, yet the passion is generally fleeting (Hatfield \& Rapson, 993).

The marriage is a commitment with love and responsibility for peace, happiness and development of strong family relationships. It is a "socially legitimate sexual union, begun with a public announcement and undertaken with some ideas of permanence; assumed with more a less explicit marriage contract, which spells out the reciprocal rights and obligations between the spouses and future children". The marital adjustment is the state, in which there is an overall feeling in husband and wife about the happiness and satisfaction with their marriage and with each other. All the marriages are aimed at happiness in one or another way. Most couple's marriages are filled up with certain expectations. Some of the expectations will be realistic while others unrealistic. This is due to the complex nature of marriage and each individual is complex as a universe. Therefore, in marriage two universes are close together that reflects the maturity growth and development in the spouse. If this growth is not experienced and realized fully, death in marital relationship is inevitable.

Thus, a coin has two sides, obverse and reverse because accomplishment of perfect love even after the marriage is not possible in every case because the attitude of jealous based on varieties of childhood complexes affect it multifariously. Psychology tends to see love as a result of the unfulfilled needs, dissatisfaction and deficiencies of the individual from the 
growing dependency on the other. In love there is jealousy and possessiveness, greed, rage, sadism and masochism, rivalry as well as competition, extremes of idealization and denigration". Jealousy is generated by a threat to, or the actual loss of a valued relationship with another person, due to an actual or imagined rival for one's partner's attention, thus is associated with a host of negative relational outcomes that results in conflict, domestic violence and divorce in general as well as suicidal ideation, behavior and attempts in particular in extreme cases. The violence of jealousy is predominantly vented on the partner rather than the actual or supposed rival. Men are responsible for the majority of the killings and serious injuries resulting from jealousy. In a recent community study of jealousy $15 \%$ of both men and women reported that they had, at some time, been subjected to physical violence at the hands of a jealous partner (Mullen \& Martin, 1994). More insecure people are, the more dependent they are on their romantic partners and mates, and the more seriously a relationship is threatened, the more fiercely jealous people will be. Couples may slap, shove, grab, bite, kick, or hit one another with their fists. They may threaten one another with knives or guns or beat one another.

Earlier Freud (1922) proposed that it is precisely when people are not at their best-when their self-esteem has been shattered, when they are anxious and afraid of and when their lives are turbulent and stressful--that they are especially vulnerable to falling head-over-heels in love. The passionate love and consuming anxiety are closely related both neuroanatomically and chemically (Hatfield \& Rapson, 1993). Erikson (1982) concluded that "anything that grows has a ground plan, and out of this parts arise, and each has its special time of ascendancy (p. 92)". In adolescence, for example, teenagers must confront two tasks: they must develop a relatively stable, independent identity and they also must learn how to participate in a loving, committed, intimate relationship. Erikson (1959) also argued that men and women may differ slightly in how easy they find it to achieve independence/intimacy. Mismatch may result suspicious and jealousy like emotion.

Thus, the jealousy is often ranked among the top three motives for non accidental homicides where motive is known-along with rage arising from a quarrel and murder during the commission of a crime. In 2003, on Valentine's Day, Texas women, Claris Harris, killed her husband after encountering him at a hotel with a mistress. She was not the only women to stand accused of murdering in a jealous rage rather on 20 November, 2014 Maria Jose, who won the title of Miss Honduras Crown on April 2014 and her sister was killed by her sister's boyfriend because she was dancing with another man. Some films that portray jealousy are Cinderella, Snow White and Toy Story. All three are Disney movies with a message of jealousy among characters. The movie Cinderella originated as a folk tale and was turned into a movie in 1950 by Walt Disney. The story line includes Lady Tremaine who was jealous of her step daughter Cinderella because of the loss of attention that she received from her husband when Cinderella was all around. The jealousy continues after Lady Tremaine's husband died and she became a widow. Lady Tremaine treats Cinderella with no respect due to her emotions of jealousy and envy. Snow White is also a folk story turned into an animated film. Walt Disney produces the story line of step mother being jealous of her step daughter now being the "fairest in the land" she was also very envious of her beauty. This 
results in the Queen, Snow White's step mom hiring a hunter to kill her and bring back her heart. The third animated Disney movie that jealousy plays a strong role in is Toy Story. Woody, the original toy that the boy owns, becomes jealous of the boy's new toy Buzz Light year. This jealousy is relevant because Woody no longer gets played with like he used to. Woody eventually overcomes his jealousy and in the end his friend with Buzz Light year.

Psychoanalysis pointed out the origin of jealousy in the triangulation of the Oedipus or Electra complex (Freud, 1922). Freud suggested that children direct their sexual urges to the parent of the opposite sex, and are ultimately defeated by the parent of the same sex. This conflict is repressed and the child identifies with the parent of the same sex to resolve it. In Freud's view, adults unconsciously relive the emotions associated with this loss when they feel what he calls "competitive" or "normal" jealousy. This view lives on in contemporary psychoanalytic theory, and accounts for the vast complexity and intensity of the emotion of jealousy, tied as it is to childhood desire and disappointment. Individuals who are frequently jealous in relationships are seen in psychoanalytic terms to have had difficulties in successfully resolving the Oedipus and Electra complexes. Lazarus (1991) pointed out that when it is not based in reality but is on the part of an individual's character, it is inappropriate and the person is often insatiable. This exaggerated, neurotic need for love is seen as rooted in infantile greed as a response to fear of loss. Lazarus (1994) drew attention to jealous individuals' propensity to interpret events in a way that influences their meaning, in that they were more likely to assume that there is something to be jealous about.

It has been theorized that individuals with narcissistic character pathology turn their sexual impulses into themselves, impairing their ability to master the oedipal phase and resulting in an exaggerated need for love to support a fragile sense of self and self-worth. There are some other varieties of jealousy (experienced in the absence of any major jealousy evoking events); reactive jealousy" (occur when concrete transgression violate critical aspects of the relationship); possessive jealousy (prevent contact of their partner with individual of the opposite sex; and in "anxious jealousy" individual cognitively generates images of a mate's infidelity, and experiences feelings of anxiety, suspicion, worry and distrust. Pfeiffer and Wong (1989) in their multidimensional jealousy theory described three types of jealousy namely emotional jealousy (perceived threat to a valued relationship); cognitive jealousy (the cognition, thoughts and worries one experience during a jealousy expression: and behavioral jealousy wherein the relationship rivals are perceived. This theory states that, the main determinant of relational satisfaction is the comparison level: one's belief about the level of outcomes they deserve from the relationship.

People evaluate their relationships as more satisfying and durable when their outcomes (rewards, punishments, and costs) are more or less equal. This means if both the mates are having extra-marital affair than the degree of jealousy will be little but if only one mate is having extra marital affair or is interested in other person then the amount of jealousy will be very high in the mate who is loyal. According to this theory, responses to relational problems such jealousy depend on the degree of each partner's willingness to take the other's outcomes into account. Rusbult's model of Exit, Voice, Loyalty, and Neglect (EVLN) is one of the most often cited approaches in coping literature, and has also been adapted to 
jealousy. The EVLN model comprises four coping styles; exit, voice, loyalty, and neglect. According to this model, exit refers to active responses that are destructive to the relationship (e.g., ending the relationship, threatening to end it, or to divorce). Exit responses tend to be most damaging to relationships. Voice involves active constructive responses that deal with the conflict, and includes expressing dissatisfaction with the aim of improving the relationship (e.g., discussing the problem, compromising). Voice responses often improve relationships. Loyalty responses represent a passive-constructive handling of the problem, characterized by waiting patiently for conditions to improve and change (one covers up the conflict and behaves in a manner emphasizing their loyalty to the relationship) (Yum, 2004). The loyalty includes waiting passively and hoping for problems to go away, and can improve relationships. Finally, neglect involves destructive and passive behaviors that allow the relationship to deteriorate. Researchers have discovered that secure people, with high self-esteem, bounce back better from the loss of love than do others and the clingy one while contemplating may be in a panic state. Of course, their partners, who have been feeling increasingly smothered by their demands may feel numb relief.

The social construction or the social construction of reality that examines the development of jointly constructed understandings of the world assumes that understanding, significance, and meaning are developed not separately within the individual, but in coordination with other human beings. The elements most important to the theory are (a) the assumption that human beings rationalize their experience by creating a model of the social world and how it functions and, the language is the most essential system through which humans construct reality. Social constructs are the by-products of countless human choices, rather than laws resulting from human judgment. The main objective of social theory (Banton, Clifford, Erosh, Lousada Rosenthal, 1985) is to understand how social or society enters into the life of an individual and construct him socially. This theory identifies three linked practices important in this process. The first is economic practice, second is political practice and the third is ideological practice. Moreover, the social theory reveals that people are subject to economic, political and ideological forces, which are more powerful than other conscious factors affecting individuals. The theory of John Bowly in (1969) is based on the bond established between mother and infant. According to him care giving experiences are internalized as working models that not only serve as a prototype for future relationship with significant others but also provide unwritten rules for how one experience expresses and copes with distressing emotions. Contemporary theory and research recognize the interconnection between attachment, care giving, and exploration for adults .

The socio-cognitive theory formulated by Albert Bandura (1977, 1986, 2001, and 2004 was an attempt to understand and predict individual and group behaviour; to identify methods in which behavior can be modified or changed and to use intervention aimed at personality development, behavior pathology and health promotion. The theory defines human behaviour as triadic, dynamic, and reciprocal interaction of personal, behavior and the environmental factors. It contends that behavior is largely regulated antecedently through the cognitive process. It involves four types of agencies named as personal where cognitive, 
motivational and affective and choice processes through which it is exercised to produce given effect. The manner in which human agency operates has been conceptualized in at least three different ways-as autonomous agency, mechanical agency and emergent interactive agency. In the concept of agency, self-referent processes are epiphenomenalism by products of conditioned responses that do not enter into the determination of action. Successful functioning requires an agentic blend of these different modes of agency. The famous spiritual leader Gandhiji also mobilizes massive collective force that bring socio political change, although lives ascetically not self-indulgently (Bandura, 2001). Thus, the aforesaid models have played a vital role in promoting marital adjustment among the partners in which there is an overall feeling in husband and wife of happiness and satisfaction with their marriage and with each other' (Thomas, 1977). All the marriages are aimed at happiness in one or another way. Most couples marry filled up with an expectation that is as complex as a universe. Therefore, in marriage two universes close knit together (Veenboven, 1983). Here maturity matters for eliciting growth and development in the spouse.

The relationship between couples is not instantaneous rather a slow and lifelong progress. It is like undetected cancer or malignant disease of love that kills silently and softly. A study was conducted on 581 couples out of which $25 \%$ disclosed that they discuss the things with each other during adjustment process whereas $18 \%$ showed serious concern on it (Leffcourt, 1976). There are approximately six areas of marital adjustment that includes religion, social life, mutual friends, in laws, money and sex (Lazarus, \& Delingis, 1983). Psychologists have added some other dimension such as values, couple growth, communication, conflict resolution, affection, roles, cooperation, sex, money and parenthood in it (Margolin, 1980). There involve a social, cultural, and psychological factors in the marital satisfaction. Beside this education, occupation and income are also associated with it (Parron, 1982). It is well stated concept that money mindedness attitude can be the best example of the jealous. A marital role comprises cultural expectations associated with the husband or with a wife. A husband is expected to provide used is considered as head of family while wife is expected to make home and companion, or the wife may be expected to be the strong one, upon whom the husband can rely (Campbell, Converse \& Rogers, 1976). Such mindset in the present scenarios has changed with changed marital adjustment.

It seems that half of the adults are suffering from severe stress blame the deteriorating relationships on their spouse after marriage. Looking at the growing rate of divorces, court cases for alimony, physical abuses and single parents; it does seem as if handling a relationship can be a tricky and often taxing issue. The possible causes can be endless. More often than not, stress arising from marital relationships is manifested in chronic disorders such as depression, insomnia and hypertension. Since a relationship depends on the nature of the persons involved, it helps to seek the middle path when the inherent individual differences surface (Weiten, 1986). Depression in a spouse is an issue that most couples will face at some point in their marriage. It is a normal and natural response to loss or grief, whether a death, separation from a loved one, job loss, loss of physical health, or relocation. Marital distress and relationship conflict also contribute to depression. Symptoms of 
depression include feelings of sadness, hopelessness, helplessness, anxiety, irritability, agitation, fatigue, low energy, and a reduced activity level are common, and there is also withdrawal from social contact and loss of interest in previously enjoyed activities, including sex. There may be changes in appetite, weight or sleep patterns, memory problems or difficulty concentrating. Often there are feelings of worthlessness or inadequacy and a lowered sense of self-esteem. In more serious cases there may be suicidal thoughts or a feeling that "life is not worth living". Married women have higher rates of depression than to unmarried women, but the reverse may be true for men. In his research Gore and Manigione (1983) while conducting a study on 695 women and 530 men in order to know the impact of depression on marital adjustment revealed that approximately $21 \%$ of the women who reported marital split during the study experienced severe depression. Thus, aim should be to keep aside the negative emotion and to inculcate positivity in relationship.

A good marriage not only produces a satisfied life but it also generates a sense of well-being. In west, marriage is often a centerpiece in ideological claims about the 'decline of family values'. Marital adjustment has been related to personality, job and home stresses, mental illness, depression, education, sex role attitude, happiness and success in life. However in Pakistan the phenomenon of marital adjustment and its related variables have not been given much attention. The prevalent form of marriages such as Brahma (in Gurukul system); Daiva (girls marriege to a priest); Arsha (the daughter is given to the Rishi or sage) ; Prajapatya ; Gandharva (exchange of garlands); Asura ( high price is given to girl parents); Rakshasa (groom fights battles with the bride's family); and Paishacha (no one considers the girl's wishes) marriages are practiced in India especially in hilly, remote and tribal areas in a mammoth. Its example is Kinnaur and upper areas of Himachal Pradesh such as the district Shimla of the state which undergo with various rudimentary customary marital practices. After marriage, these couples undergo with the jealous. Women have an easy time learning to be close to others; they have more trouble learning how to be independent. Other theorists have agreed. Men and women who are secure have been found to fall passionately in love fairly often. A steady personality does not guarantee smooth sailing in stressful romantic waters, of course.

Thus, it seems that the love is difficult for everyone and the vast majority of love affairs fail. Nonetheless, the secure do seem to do better than most at negotiating stable, companionate, intimate love relationships. Secure people think of themselves as valuable and worthy of others' affection and concern. They assume their romantic partners are wellintentioned, trustworthy, reliable, and available. The women are the most essential part of our society; without women our society cannot move. The causes of mental disorder were domestic violence, exchange marriages, marriages as migration from rural to urban areas, none of cultural adjustment. Environmental factors which included in mental illness are death or divorce, a dysfunctional family life, sex selection abortion, when try to finish the right/freedom of females, poverty, feeling of inadequacy, low self esteem, anxiety, anger, or loneliness, social or cultural expectations, women violence and discrimination. These factors may in turn play an important role in domestic violence. 
The domestic violence is a pattern of behavior in which one intimate partner uses physical violence, coercion, threats, intimidation, isolation and emotional, sexual, or economic abuse to control the other partner in a relationship. Even in the new millennium, women in South Asia are deprived of their socio-economic and legal rights. Some ancient traditions and customs are still followed promoting various forms of violence against women. These include honor killing, exchange marriages, marriage to Quran, bride price, dowry, female circumcision, questioning women's ability to testify, confinement to home, denying their rights, the practice of Sati. T mental, psychological and emotional abuse can be verbal or nonverbal. Verbal or nonverbal abuse of a spouse or intimate partner consists of more subtle actions or behaviors than physical abuse. While physical abuse might seem worse, the scars of verbal and emotional abuse are deep. Studies show that verbal or nonverbal abuse can be much more emotionally damaging than physical abuse. Verbal or nonverbal abuse of a spouse or intimate partner may included on threatening or intimidating to gain compliance, destruction of the victim's personal property and possessions, or threats to do so, violence to an object, in the presence of the intended victim, as a way of instilling fear of further violence, yelling or screaming, name-calling, constant harassment, embarrassing, making fun of, or mocking the victim, either alone within the household, in public, or in front of family or friends, criticizing or diminishing the victim's accomplishments or goals, not trusting the victim's decision-making, telling the victim that they are worthless on their own, without the abuser, excessive possessiveness. National Health and Medical Research Council stated that the women who experience gender-based violence such as rape, sexual assault, intimate partner violence and stalking have a higher lifetime prevalence of mental health disorders, dysfunction and disability. According to Ann (2015) the sexual aggression is highest among Indian youth. The National Crime Records Bureau also confirms the same by stating the example that 90 women are raped in India every day. Hence, such behavior affects marital life of the couples.

There might be various socio-psychological fact ors involved in such a relationship. The people sometime in drug and substance consumption state e.g. consumption of alcohol may enmesh in such relationship (Sharma \& Zinta, 2008). In South Indian Tamil families, for example, a person who falls head-over-heels in love with another is said to be suffering from Mayakkam-dizziness, confusion, intoxication, and delusion. The wild hopes and despairs of love are thought to "mix you up" (Trawick, 1990). If mismatched, it may results in jealousy that in turn become may become violence and sometime can end with murder. So imagine how dangerous the jealous is that in present day is causing marital dissatisfaction amongst the couples. It has resulted insecurity, fear, and anxiety thus involves anger, resentment, inadequacy, helplessness and disgust. It has compounded in grief, narcissistic wound, enmity against the successful rival, and an amount of self-criticism. Other theorists have included anger, aggression, hatred, rage, envy, revenge, fear, apprehension, anxiety, panic, suspicion, mistrust, expectancy, distress, depression, self-pity, guilt, love, and sexual arousal" in it (White \& Mullen, 1989). 


\subsection{Present study and objectives}

Jealousy, the shadow of love and green eyed-monster that on the one hand has ruined marital adjustment of millions of couples by creating fraction amongst the families and on the other also seems equally beneficial for promoting the La Dolce Vita philosophy of happiness amongst the couples across the world. It seems that foremost source of this covetous issue might be the insecurity and fear of being abandoned by one of the partner due to extra marital relationship, excessive flow of money, poverty that push away the people to leave sedentary mode of life and to adopt nomadic way, mismatch of thoughts, emotions and behavior, and values of life, over involvement, much or less care, violation of customary practices, eating and sleeping habits, pro-social attitude, less mindfulness and more money mindedness; selfishness, performing job and business outside the native place may results in jealous that may hamper their marital relationship in general and personal development in particular. Once a time when there use to be a faith and sacred relationship in marriage in India, that in contemporary Kaliyug scenario has faded away and converted into suspiciousness and jealousy. The level of jealous may differ among the working and nonworking people in general and the rural and urban men and women in both developed and developing countries as well as in hilly areas like Himachal Pradesh where the people were very honest now has followed the path of astuteness that has disturbed the marital homeostasis.

In the present study a pioneer attempt has been made to explore the relationship between jealousy and marital adjustment. As a result, it seems to have affected the marital life adjustment of millions of people by increasing allostatic load, psychological distresses like depression and anxiety related vulnerabilities and suicidal tendencies behavioral and practices amongst the married couple. It has proved one of the factor in ruining the already well established families thereof has affected marital adjustment amongst the couples. It is one of the reasons of divorce, suicides ideation and behavior and marital distress and extreme depression amongst the couples. Generally, it seems that the jealousy happens when a person feels that a relationship that is of prime importance is threatened by someone else outside of the relationship, be it romantic, platonic, friendship, parent-child, and sibling related. It has resulted marital discord amongst the marital adjustments of the youngest couples who are the backbone of the Nation. This situation remained status quo among the people living in both in rural or urban areas, whether they are educated or illiterate, employed as well as un-employed. The evidence of such suspicious jealousy seems to be present since time immemorial in Vedas and Purana such as jealous of Lord Ramas to towards Sita as well as of Radha and Meera towards Lord Krishna. The suspicious like emotion involved in the jealous have increases allostatic load amongst the couples that in turn has affected marital flavor and adjustment of the people in the contemporary scenarios. Thus, the main objective of the present study is to identify the difference between rural and urban working and non working men and women on the measures of jealousy and marital adjustment. For accomplishing the objectives following methodology has been adopted. Description is as follows:- 


\subsection{Methodology}

1.3.1 Study Area: The study has been conducted in the rural areas of villages Samroti, Loshta, and Shawat of rural areas Kotgarh and Panthaghat, Bharari, Taradevi urban areas of district Shimla. Therefore, both rural and areas falls in district Shimla which is the capital city of Himachal Pradesh have been selected in the present study. It is popularly known as Dev Bhumi i.e. the place of gods and goddesses. It is spread over 21,495 sq miles (55,670 km2), and is bordered by Jammu and Kashmir on the North, Punjab on the West and South-West, Haryana and Uttrakhand on the South-East and by Tibet on the East.

1.3.2 Sample: The present study has been conducted in both rural and urban area of Shimla district which is the capital of Himachal Pradesh. The study has been conducted on $\mathrm{n}=200$ married couples. From the aforesaid sample $n=100$ subjects have been selected from rural area and $n=100$ have been selected from urban areas. These two groups have been divided further into two sub-groups based on Employment that comprises of $n=50$ working and $n=$ 50 non- working in each group. Finally these subjects have further been subdivided into two more sub-groups based on Gender that comprises of $n=25$ in men and another $n=25$ in women categories. Thus, there are 8 group (Urban Working Men, Urban Non-Working Men; Urban Working Women; Urban Non-Working Women; Rural Working Men, Rural NonWorking Men; Rural Working Women; and Rural Non-Working Women) with $n=25$ subjects in each group that comprises of aforesaid sample of $n=200$ married people.

1.3.3 Measures: The subjects in the present study have been assessed both quantitatively and qualitatively. The quantitative measures include Multidimensional Jealous Scale, and Revised Dyadic Adjustment Scale. Descriptions of quantitative measure are as follows:-

1.3.3a: Multidimensional Jealousy Scale: It was developed by Susan M. Peiffer and Paul T.P. Wong in 1989. It consists of 24 items which were divided into 3 parts: cognitive, emotional and behavioral one that contains 8 items. All the items have been evaluated on seven point scale. For each part the score ranges from minimum of 8 to maximum of 56 in each part. Reliability of this scale ranged from $r=.83$ to $r=.92$. This scale is used because it measures the jealousy on emotional, cognitive and behavioral dimensions and will clearly tell that whether a person is high on cognitive jealousy or emotional or behavioral jealousy.

1.3.3b: Revised Dyadic Adjustment Scale: It was developed by Busby, Christensen, and Larson in 1995. It contains 14 items. Each statement has been evaluated on five and six point scale. The item Number 11 has five point options. Thus, the score ranges from a minimum of 0 to maximum of 69. Higher score indicate greater stability and satisfaction in the relationship. Reliability of scale $r=0.90$. It is used because it is a straightforward assessment that can be completely easily and in a short amount of time. It can successfully differentiate between 
distressed and non-distressed relationship and it will clearly tell that whether a person is well adjusted in their married life or not.

\subsection{Procedure}

The present study has been conducted in the rural and urban areas of Shimla district of Himachal Pradesh. More appropriately the villages of Kotgarh areas and nearby Shimla city have been selected. The Kotgarh is situated approximately $82 \mathrm{~km}$ from Shimla and is famous for its apples orchards production. It is also known as 'Apple bowl of India'. Further the people of Shimla city have also been explored. From both rural and urban areas the employed and unemployed peoples have been selected. The selected people have been assessed in terms of jealousy and marital adjustment. The objective of the study was to assess the level of jealousy and marital adjustment among the rural and urban working and non working people of Shimla district. The present study has been conducted in the rural and urban area of Shimla district which is the capital of Himachal Pradesh. The study has been conducted on a sample of $n=200$ married couples. From the aforesaid sample $n=100$ subjects have been selected from rural area and $n=100$ have been selected from urban area. These two groups have been divided further into two sub-groups based on gender that comprises of $n=50$ men and $n=50$ women in each group. Finally, these subjects have further been subdivided into two more sub-groups based on Employment Status that comprises of $\mathrm{n}=25$ in working and another $\mathrm{n}=25$ in non-working categories. Thus, there were 8 group (Urban Working Men, Urban Non-Working Men; Urban Working Women; Urban Non-Working Women; Rural Working Men, Rural Non-Working Men; Rural Working Women; and Rural Non-Working Women) with $n=25$ subjects in each group that comprises of aforesaid sample of $n=200$ married people. These subjects have been assessed on the Jelousy and Marital adjustment scales after taking their consent. The subjects were apprized about the purpose of the study. They were assured that their name will be kept secret and confidentiality will be made. Hence ethics while conducting this piece of research were maintained. The data was gathered, tabulated, scored, analyzed and interpreted by applying appropriate statistics .

\subsection{Result}

In this section a pioneer attempt has been made to assess the jealousy and marital adjustment among rural and urban areas working and non-working people. In the below mentioned section attempt has been made to observe the degree of jealous and marital adjustment among rural as well as urban working and non-working men and women. Average scores have been calculated to see the level of jealous in both urban and rural people; working and non-working people as well men and women separately. Jealousy is regarded as one of the intense, prevalent and worrisome feeling in intimate relationship. It is associated with various factors different words, meanings and images. It is complicated reaction in response to threat which would end or destroy a relationship that is considered important. It is an unpleasant emotional reaction based on the relationship between an 
individual current or previous partner and a third person. It has been considered the results of low self-esteem and feeling of insufficiency. The level of jealousy decreases when the satisfaction in a relationship increases. It comes from feeling impoverished in our own minds. It comes from being totally self focused. When we feel jealous we hold the belief or misunderstanding that focusing on ourselves will bring happiness, whereas, in truth when we extend love and care toward others we experience a much greater sense of joy and inner richness. It is not what we need to ignore own needs, but just to understand that focusing solely on ourselves causes pain. In the Table 1.1 a pioneer attempt has been made to assess the level of jealousy among urban and rural working men and women.

\section{TABLE 1.1}

Average Score of Urban and Rural Working and Non Working Men and Women on the Measure of Jealousy

\begin{tabular}{|l|l|l|l|l|}
\hline \multirow{2}{*}{ Group } & M & WM & AV \\
\hline \multirow{4}{*}{ Urban } & W & 70.84 & 71.16 & 71.00 \\
\cline { 2 - 6 } & NW & 69.76 & 68.40 & 69.08 \\
\cline { 2 - 6 } & Av. & 70.30 & 69.78 & 70.04 \\
\hline \multirow{4}{*}{ Rural } & W & 70.60 & 67.92 & 69.26 \\
\cline { 2 - 5 } & NW & 68.20 & 68.12 & 68.16 \\
\cline { 2 - 5 } & Av & 69.40 & 68.02 & 68.71 \\
\hline
\end{tabular}

Notations: U=Urban, R=Rural, $M=$ Men, WM=Women, $W=$ Working, $N W=$ Non Working, AV=Average

The average score of the people of Urban area on the measure of Jealousy was 70.04 and the average score of Rural area on the measure of Jealousy was 68.71. This means Urban people were more in Jealous behavior than Rural people. The average score of Men on the measure of Jealousy was 69.85 and the average score of Women was 68.90. It means Men were more Jealous than to Women towards their partner. This may be because men have always a thought in the back of their mind that their partner is cheating on them as they are not able to give them sufficient time. Sometimes it is due to inferiority complex and sometimes after seeing relationship status around them. The average score of working people on the measure of jealousy was 70.13 and the average score of Non Working people on the measure of Jealousy was 68.62. This means that Working people are more Jealous than Non Working people towards their partner. It might due to lack of enough time to their partner and thus they think that someone else can make their partner more happy and satisfied and Jealousy may also arise in them after seeing other's people relationship status around them. 
The average score of Working Men and Women in Urban area on the measure of Jealousy was 71 and the average score of Non Working Men and Women in Urban area on the measure was 69.08. This means Working people are more Jealous than Non Working people. The average score of Working Men was 70.84 and those of Non-working Men was 69.76. It means Working men were more Jealous in their relationship as compared to Non Working Men. The average score Working Women was 71.16 and of Non Working Women as 68.40. This means Working Women are more Jealous in their relationship as compared to Non Working Women. The average score of Working Men was 70.84 and those of Working Women was 71.16. This means Working Women were more Jealous than Working Men. The average score of Non Working Men was 69.76 and those of Non Working Women was 68.40. This means Non working men are more Jealous as compared to Non-working Women. The average score of Working Men was found 70.84 and Non-working Women as 68.40 respectively. This means that Working Men are more Jealous than Non-working Women. The average score working women was 71.16 and those of non working men is 69.76. This means Working Women are more Jealous as compared to No- working Women.

The average score of Working Men and Women in Rural area on the measure of Jealousy was 69.26 and the Non working Men and Women in Rural area as 68.16. The average score of Working Men was 70.60 and those of Non working Men as 68.20. This means Working Men were more Jealous than to Non working Men. The average score of Working Women was 67.92 and the average score on non working women was 68.12. The average score of Working Men was 70.60 and those of Working Women as 67.92. This means Working Men were more in Jealous than to Working Women. The average score of Non working Men was 68.20 and those of Non working women as 68.12. It means Non working Men are more Jealous than Non working Women. The average score of Working men was 70.60 and those of Non working Women was 68.12. This means Working men were more in Jealous than to Non working Women. The average score of Working Women was 67.92 and the average score of Non working Men was 68.20. This means Non working men are more Jealous as compared to Working Women. The overall findings suggested that Urban people were more Jealous than Rural people and Men showed more Jealousy than to Women and one of the consistent findings was that Working people showed more Jealousy than to Non Working people. Scientific studies differ slightly on this issue. But in $2 \times 2 \times 2$ ANOVA as depicted in Table 1.2, a non-significant relationship was observed whose description is as follows:-

\section{Table 1.2}

A 2 X 2x 2 ANOVA Performed on the Measure of Jealousy among Rural and Urban Working and Non Working Men and Women of Shimla District

\begin{tabular}{|l|l|l|l|l|l|}
\hline SOURCE & SS & $d f$ & $\mathrm{~ms}$ & $\mathrm{~F}$ & $\mathrm{P}$ \\
\hline TOTAL & 990429.000 & 200 & & & \\
\hline L & 88.445 & 1 & 88.445 & .617 & n.s. \\
\hline
\end{tabular}




\begin{tabular}{|l|l|l|l|l|l|}
\hline & & & & & \\
\hline S & 45.125 & 1 & 45.125 & .315 & n.s. \\
\hline ES & 114.005 & 1 & 114.005 & .795 & n.s. \\
\hline Lx S & 9.245 & 1 & 9.245 & .064 & n.s. \\
\hline Lx ES & 8.405 & 1 & 8.405 & .059 & n.s. \\
\hline S x ES & 2.645 & 1 & 2.645 & .018 & n.s. \\
\hline Lx S X ES & 57.245 & 1 & 57.245 & .399 & n.s. \\
\hline ERROR & 27525.760 & 192 & & & \\
\hline
\end{tabular}

Notations: L=Locality, S=Sex, ES=Employment Status

Main effect of Locality on the measure of Jealousy was found $F(1,192)=.617, p>.05$, as statistically non significant. It shows that there is no significant difference between rural and urban people on the measure of Jealousy. More appropriately the average score of urban people was found 70.04 and rural were found 68.71. Although there is slight difference between two groups yet Analysis of Variance applied on the measure of jealousy has revealed non-significant difference. But main effect of Sex on the Jealousy was also found $F$ $(1,192)=.315, p>.05$, as statistically non-significant. It shows that there is no significant difference between Men and Women on the measure of Jealousy. More appropriately the average score of Men was found 69.85 and the average score of Women was found 68.90. Main effect of Employment Status on the Jealousy was found $F(1,192)=.795, p>.05$, as statistically non- significant. It shows that there is no significant difference between Working people and Non Working people on the measure of Jealousy. More appropriately the average score of Working people was found 70.13 and the Non Working people were as 68.62. The two way interaction between Locality and Sex on the Jealousy was found $F$ $(1,192)=.064, p>.05$, as statistically non-significant. But the interaction between Locality and Employment Status on the Jealousy was found $F(1,192)=.059, p>.05$, as statistically nonsignificant and interaction between Sex and Employment Status was also found $F(1,192)$ $=.018, p>.05$, as statistically non-significant. Similarly, Three way interaction between Locality, Sex and Employment Status on the Jealousy was found $F(1,192)=.399, p>.05$, as statistically non- significant.

\subsection{Analysis of Marital Adjustment among Rural and Urban Working and Non Working Men and Women}

Marital adjustment is a process during which partners in a marriage adapt and changes to their new roles complementing each other acting as a team opposed to two separate units. 
It is also important that in a marriage couple should unify the interests and values, maintaining open lines of communication and encouraging the expression of each other communication. It is state in which there is an overall feeling in husband and wife of happiness and satisfaction with their marriage and with each other. Marital adjustment calls for maturity that accepts and understands growth and development in the spouse. If this growth is not experienced and realized fully, death in marital adjustment is inevitable. Interpersonal conflict among people at work has been shown to be one of the most frequently noted stressors for employees. Conflict has been noted to be an indicator of the broader concept of workplace harassment. It relates to other stressors that might co-occur, such as role conflict, role ambiguity, and workload. It also relates to strains such as anxiety, depression, physical symptoms, and low levels of job satisfaction. It has also been found that working women undergo lot of stress, even more than working men because they have to balance their life between their office responsibilities and home responsibilities thus making their life full of conflicts and tension and leading to maladjustment in married life.

Table 1.3

Average Score of Urban and Rural Men and Women working and Non Working on the Measure of Marital Adjustment

\begin{tabular}{|l|l|l|l|l|}
\hline \multirow{2}{*}{\multicolumn{2}{|l|}{ Group }} & M & WM & AV \\
\hline \multirow{4}{*}{ Urban } & W & 51.28 & 51.56 & 51.42 \\
\cline { 2 - 6 } & NW & 54.92 & 53.92 & 54.42 \\
\cline { 2 - 6 } & Av. & 53.10 & 52.74 & 52.92 \\
\hline \multirow{4}{*}{ Rural } & W & 51.32 & 54.84 & 53.08 \\
\cline { 2 - 6 } & NW & 51.24 & 47.24 & 49.24 \\
\cline { 2 - 5 } & Av & 51.28 & 51.04 & 51.16 \\
\hline
\end{tabular}

Notations: U=Urban, $R=$ Rural, $M=$ Men, WM=Women, $W=$ Working, $N W=$ Non Working, $A V=$ Average

The average score of Urban area on the measure of Marital adjustment was 52.92 and the average score of Rural area in the measure of Marital adjustment was 51.16.This means Urban area has better adjusted marital life than to Rural area. The average score of Men on the measure of Marital adjustment was 52.19 and the average score of Women on the measure on Marital adjustment was 51.89. It means that Men have well adjusted marital life 
than to Women. This is because Men can easily balance their time and space between their family, friends and work as compared to Women. The average score of Working people on the measure of Marital adjustment was 52.25 and Non Working people on the measure of marital adjustment as 51.83. This means Working people have better adjusted marital life than non Working people. It may be because of independence in their life the Working people have and power than Non Working people in both Rural and Urban areas.

The average score of Men and Women Working in Urban area on the measure of Marital adjustment was 51.42 and that of Non Working Men and Women was 54.42. This means Non Working people have well adjusted marital life than Working people. The average score of Working Men was 51.28 and that of Non Working Men was 54.92. It means Non Working Men are more adjusted in their lives. This is because they do not bear so much of stress as compared to Working men. The average score of Working Women was 51.56 and that of Non Working Women was 53.92. It means Non Working Women were well adjusted because of the same reason as they do not bear that much of stress because they do not have to bear dual responsibilities of office and home. According to the work done by Dhanraj Singh Slathia (2014), working women faces more marital problem in a greater degree than Non Working Women because of the added responsibilities of job may suffer from more severe cause of maladjustment at home or in office. The average score of Working Men was 51.28 and that of Working Women as 51.56. It means Working Women were well adjusted in their lives as compared to Working Men. This may be because they enjoy more their role than Men. The average score of Non Working Men was 54.92 and that of Non Working Women was 53.92. This means Non Working Men enjoyed more their life and were well adjusted than Non Working Women. The average score of Working Men was 51.28 and that of Non Working Women was 53.92. It means Non Working Women were well adjusted in their life than Working Men. The average score of Working Women was 51.56 and that of Non Working Men was 54.92. This means Non Working Men were well adjusted than Working Women.

The average score of Working Men and Working Women on the measure of Marital adjustment in Rural area was 53.08 and that of Non Working men and Non Working Women in Rural area as 49.24. It means Working people have well adjusted life than Non Working people. The average score of Working Men was 51.36 and that of Non Working Men was 51.24. This means Working Men has well adjusted marital life than Non Working Men. This may be because they handle their financial problems well. The average score of working women was 54.84 and those of Non Working Women was 47.24. It means Working Women have well adjusted marital life because they are financially strong and more satisfied as compared to non working Women. The average score of Working Men was 51.36 and that of Working Women was 54.84. This means Working Women were more adjusted in their life. The average score of Non Working Men was 51.24 and that of Non Working Women was 47.24. This means Non Working Men have well adjusted life than Non Working Women as are free from all kinds of tensions and worries. The average score of working men was 51.36 and that non working woman as 47.24. This means Working Men are better adjusted in their life they are independent in terms of income as well as thoughts. The average score of 
Working Women was 54.84 and that of Non Working Men was 51.24. This means Women were better adjusted in their life as compared to Non Working Men. Thus overall it was found out that Urban people have better adjusted married life than Rural people. In case of gender in present study Men were found better adjusted in their married life and in case of Employment Status; Working people were found high on better adjusted married life. Analysis of Marital Adjustment has been given in the below mentioned table 1.4 whose description is as follows:-

\section{Table 1.4}

A 2 X 2 X 2 ANOVA performed on Marital Adjustment among Rural and Urban Working and Non Working Men and Women

\begin{tabular}{|l|l|l|l|l|l|}
\hline SOURCE & Ss & $\mathrm{df}$ & $\mathrm{ms}$ & $\mathrm{F}$ & $\mathrm{P}$ \\
\hline TOTAL & 563417.000 & 200 & & & \\
\hline L & 153.125 & 1 & 153.125 & 1.430 & n.s. \\
\hline S & 4.805 & 1 & 4.805 & .045 & n.s. \\
\hline ES & 9.245 & 1 & 9.245 & .086 & n.s. \\
\hline L X ES & .125 & 1 & .125 & .001 & n.s. \\
\hline S X ES & 2388.245 & 1 & 588.245 & 5.492 & $<.05$ \\
\hline L x S X ES & 120.125 & 1 & 239.805 & 2.239 & n.s. \\
\hline ERROR & 20565.120 & 192 & 107.110 & 1.122 & n.s. \\
\hline
\end{tabular}

Notations: L=Locality, S=Sex, ES=Employment Status

Main effect of Locality on the Marital Adjustment was found $F(1,192)=1.430, p>.05$, as statistically non-significant. It shows that there is no significant difference between Urban people and Rural people on the measure of Marital Adjustment. More appropriately the average score of Urban people was found 52.92 and Rural people were found 51.16. Main effect of Sex on the Marital Adjustment was found F $(1,192)=.045, p>.05$, as statistically nonsignificant. It shows that there is non-significant difference between Men and Women on the measure of Adjustment. More appropriately the average score of Men was found 52.19 and Women were found 51.89. Main effect of Employment Status on the Adjustment was found $F(1,192)=.086, p>.05$, as statistically non-significant. It shows that there is nonsignificant difference between Working people and Non Working people on the measure of 
Adjustment. More appropriately the average score of Working people was found 52.25 and Non working people was found 51.89. Two way interaction between Locality and Sex on the Adjustment was found $F(1,192)=.001, p>.05$, as statistically non significant. Two way interaction between Locality and Employment Status on the Adjustment was found $F(1,192)$ $=5.492, \mathrm{p}<.05$, as statistically significant. It shows that Urban people have well adjusted marital life as compared to their Rural counterpart and Working people have well adjusted marital life as compared to their Non working counterpart. Two way interaction between Sex and Employment Status on the Adjustment was found $F(1,192)=2.239$, $p>.05$, as statistically non-significant and three way interaction between Locality, Sex and Employment Status on the Adjustment was found $F(1,192)=1.122, p>.05$, as statistically nonsignificant.

\section{Conclusion}

Jealousy, the shadow of the love and green eyed-monster that on the one side has ruined the marital adjustment of millions of couples by running their families and on the other hand seems equally beneficial for promoting the La Dolce Vita for promoting the happiness among the couples. The level of jealous may differ among the working and non-working people in general and the rural and urban men and women in particular. In the present study a pioneer attempt has been made to explore the relationship between jealousy and marital adjustment among 200 Working and Non-Working Couples Of Rural and Urban areas of Himachal Pradesh. Thus 8 groups namely Urban Working Men, Urban Non-Working Men; Urban Working Women; Urban Non-Working Women; Rural Working Men, Rural NonWorking Men; Rural Working Women; and Rural Non-Working Women with $\mathrm{n}=25$ subjects in each group have been formed. These subjects were assessed with the help of Multidimensional Jealousy Scale developed by Susan M. Peiffer and Paul T.P. Wong in 1989's 24 on seven point scale of eight items wherein the score ranges from minimum of 8 to maximum of 56 with the reliability of $r=.83$ to $r=.92$ respectively. The marital adjustment was measured with the Revised Dyadic Adjustment Scale as developed by Busby, Christensen, and Larson in 1995 that has 14 items with five and six point scale ( e.g. item 11 has five point options). Thus, the score ranges from a minimum of o to maximum of 69 with reliability of $r=0.90$. The result revealed that Men reported well adjusted marital life; but were more Jealous than to Women. Its reason seems to be that the men are always outside from their native place and home for providing livelihood amenities to their families and children. From their heart they are at their home and by their body they are outside. Further, it seems that the men are more emotional, do more care of their wives as well as a honest thereof are more attached to her. The separation results them in anxiety on the one hand and the suspiciousness and jealousy on the other. Because, they are in the apprehension that the wife alone may form sexual or intimate relationship with other. In this way it seems that they although are physical very strong yet it can be hypothesized that they are psychologically weak from their thoughts and emotions. Another reason for such seriousness may be their more field exposures and interaction with various segments of people in general and women in particular. The generalization of attitude they learned in 
certain city life like in brothel may also causes such suspiciousness and jealousy attitude towards their partners.

The Non Working Men enjoyed their life, were well adjusted but reported more Jealous as compared to Non-working Women. From this finding it is generalized that the non-working people live and pass their life easing in gossiping way despite they have less money. They spent it for their own beautification, eating and drinking. The working people however have much money but are miser in lieu of their aspiration for better quality of life. The poor couples always are in a fear that when their husband and wife will encounter with richer one, those also are handsome or beautiful may cause extra marital relation.

The Urban people reported better adjusted marital life but more jealousy than to Rural area. The Women were better adjusted in their life. The urban people have more exposure and interaction with the men and women. The intimacy may arise while continuing interaction. It may turn into live relationship that in turn may result in suspiciousness and jealousy. It seems that foremost source of this covetous issue might be the insecurity and fear of being abandoned by one of the partner due to extra marital relationship, excessive flow of money, poverty that push away the people to leave sedentary mode of life and to adopt nomadic way, mismatch of thoughts, emotions and behavior, and values of life, over involvement, much or less care, violation of customary practices, eating and sleeping habits, pro-social attitude, less mindfulness and more money mindedness; selfishness, performing job and business outside the native place may results in jealous that may hamper their marital relationship in general and personal development in particular.

Once a time when there use to be a faith and sacred relationship in marriage in India, that in contemporary Kaliyug scenario has faded away and converted into suspiciousness and jealousy. The level of jealous may differ among the working and non-working people in general and the rural and urban men and women in both developed and developing countries as well as in hilly areas like Himachal Pradesh where the people were very honest now has followed the path of astuteness that has disturbed the marital homeostasis. When a person feels jealous then insecurity arises inside them. Feeling of insecurity usually arises when one member of relationship questions the feelings of other and also arises due to lack of attention from one's partner and also if one partner has low self-esteem and little selfconfidence and due to low self esteem jealousy may also arise due to small harmless stimuli such as one's partner talking to member of opposite sex. So to reduce jealousy one should boost their self esteem and their partner can also build's their confidence and tell them about their love and why he/she wouldn't want to be someone else.

Fear of losing one's partner also triggers the feeling of jealousy. Having an awareness that one can lose one's partner can actually strengthen the bonds between couples but not when this feeling become obsessive or irrational. So if reassurance can be given by one's partner time and again then this feeling can be reduced. Feeling of competition also leads to jealousy between the partners when both are working. This leads to conflict between them. In order to avoid this feeling both partner should feel happy by other success and should motivate one another to do better in their job instead of proving themselves better. 
Nowadays social networking sites are also playing a major role in creating problems between the couples. Instead of giving time to each other, partners are using that time on these sites which are causing insecurity in relationship and according to a new study breakups and divorce has increase due to this. So cutting back to moderate and healthy use of these sites, one can reduce the feeling of jealousy and conflict between each other. If you have a jealous spouse than first of all you should find out that what you are doing that is provoking the feeling of jealousy in your partner and then stop doing that activity for some time to show your spouse that you are committed to your marriage relationship but avoid making promises that you cannot keep and be expressive in love toward your spouse and talk openly about the problem and work together to find a solution. If you are a jealous spouse, than be with honest your feeling. Don't manipulate them and ask yourself what is the cause of feeling.

Think positive about your spouse and remind yourself that your partner loves you, is committed to you and does respect you. Bite your lip, take a moment before making any small comments or giving a 'look' count to 10 and see how you feel after the moment has passed. When one feel jealous then set aside a certain time of day, every day, which you will call your 'worry time' or 'jealousy time'. For example you will set aside 7 pm every time for 15 minutes. At all other times you must tell yourself not to indulge in worry because it not your worry time and when your worry times arrives, you can choose whether to worry or not. Chances are you may decide to spend your time, more fruitfully. By giving yourself permission to worry later, you are much more likely to be successful in postponing and reducing jealousy. Mindfulness is a best technique one should practice to reduce jealousy. By mindfulness, the main idea is to recognize that a thought is not a fact, it is just something going in your brain and it may have no connection with the reality. A little jealousy, occasionally, is a natural emotion and can be positive in small doses, but if left unchecked it can become intense, irrational and very destructive. So if nothing is working out in reducing jealousy than one should contact a well-trained CBT (Cognitive Behavior Therapy) therapist who can help how to cut down the feeling of jealousy. For curving this significant issue of jealous there is a need to share the problem, increase the interpersonal communication, to follow compromising life, avoid hard punishment, avoid drugs, be Satvik, honest, keep their partner happy by showing them the temple, tourists destinations, keep themselves busy in work, keep tight control on their emotions, learn to know the right conversation at right time, not to disclose the love relationship of pas, convince them to see TV and Movie, providing them the less of morality and spirituality. Anyhow if certain people are enmeshed much more then there is a need for rehabilitation for which the government should take favorable move to curve this covetous issue of jealous so as to bring happiness amongst the couples. One must stop comparing yourself with others; and should have patience and wait.

One should report to their partner that you are in jealous. One should use key words like "At this moment" or "Today, I am upset because I saw you talking with somebody". If you are going to be pointing fingers and getting jealous, make sure you aren't committing the same mistakes as well. Stay away from ex-flames, flirts and men who have a knack of hitting on you all the time. Just because you're jealous don't do the same thing to him. In simple 
words, do not 'get back' at your man or woman or play fire with fire. You are the superior one and you have an ego the size of the country, but remember absolutely no good is going to come out of being vindictive. There's nothing that can't be solved with a conversation. So talk it out. Don't raise your voice, improve your argument rather. Devote much time for your partner, have a picnic, spent some money for caring your wife. Further concept clarification through discussion, care, help in kitchen, maintaining proximity, purchasing certain gifts, suits and jewellery, certain bank balance in the name of opposite partner as well as caring parents may rebuilt confidence and reduce jealousy.

\section{References}

Ainsworth, M. D. S. (1989). Attachments beyond infancy. American Psychologist, 44, 709716. http://dx.doi.org/10.1037/0003-066X.44.4.709

Bandura, A. (1977). Social learning theory. Engelwood Cliffs, Nj: Prentice hall.

Bandura, A. (1986). Social foundations of thought and action: A social cognitive theory. Englewood Cliffs, NJ: Prentice- Hall, Inc.

Bandura, A. (2001). Social cognitive theory: An agentic perspective. Annual review of psychology (Vol. 52, pp. 1-26). Palo Alto, CA: Annual Reviews.

http://dx.doi.org/10.1146/annurev.psych.52.1.1

Bandura, A. (2004). Health promotion by social cognitive means. Health Education \& Behavior. http://dx.doi.org/10.1177/1090198104263660

Banton, R., Clifford, P., Foosh, S., Lusada, J. \& Rosenthall, J. (1985). The politics of mental health. London: Macmillan.

Bartels, A. \& Zeki, S. (2000). The neural basis of romantic love. Neuroreport,11, 3829-3834. http://dx.doi.org/10.1097/00001756-200011270-00046

Bowlby, J. (1969), Attachment and loss, Vol. 1: Attachment. New York: Basic Books.

Buunk, B. P. (1991). Jealousy in close relationships: An exchange-theoretical perspective. In P. Salovey (Ed.), The psychology of jealousy and envy (pp. 148-178). NY: Guilford Press.

Campbell, A., Converse, P. E. \& Rogers, W. L. (1976). The quality of American Life. New York: Russel Sage Foundation.

Carter, C. S. (1998). Neuroendocrine perspectives on social attachment and love. Psychoneuroendrocrinology, 23, 779-818. http://dx.doi.org/10.1016/S0306-4530(98)00055-9

Comer, R. J. (1996). Abnormal psychology 2nd edition. USA: WH Freeman \& Company. USA. 
Fischer, K. W., Shaver, P. R., \& Carnochan, P. (1990). How emotions develop and how they organize development. Cognition \& Emotion, 4, 81-127.

http://dx.doi.org/10.1080/02699939008407142

Fisher, H. E. (2004). Why We Love: The nature and chemistry of romantic love. New York: Henry Holt and Company.

Freud, S. (1922). Some neurotic mechanisms in jealousy, paranoia and homosexuality. In J. Strachey (Ed. \& Trans), The standard edition of the complete psychological works of Sigmund Freud, 18; pp. 221-232).

Gore, S., \& Manigione, T. W. (1983). Social roles, sex roles, and psychological distress: Additive and interactive models of sex differences. Journal of Health \& Social Behavior 24, 300-312. http://dx.doi.org/10.2307/2136397

Hashmi, H. A. , Khurshid, M. \& Hassan, I. (2007). Marital Adjustment, Stress and Depression among Working and Non-Working Married Women. Internet Journal of Medical Update, 2 (1), 19-26. http://dx.doi.org/10.4314/ijmu.v2i1.39843

Hatfield, E. \& Rapson, R. L. (1993). Love, sex, and intimacy: Their psychology, biology, and history. New York: Harper Collins.

Hatfield, E. \& Rapson, R. L. (1996). Love and sex: Cross-cultural perspectives. Boston, MA: Allyn \& Bacon.

Hatfield, E. (2008). Romance. In William A. Darity (Ed.). International Encyclopedia of Social Sciences, 2nd Edition. Volume 7. (pp. 281-282). New York: MacMillan.

Jankowiak, W. R. \& Fischer, E. F. (1992). A cross-cultural perspective on romantic love. Ethology, 31, 149-155. http://dx.doi.org/10.2307/3773618

Johnson, D. (2010). Love: Bondage or liberation? A psychological exploration of the meaning, values, and dangers of falling in love. London: Karnac.

Kernberg, O. (1975). Borderline conditions of pathological narcissism. New York, NY: Jason Aronson.

Lavenson, R. W., Cartenson, L. L., \& Gottman, J. M. (1995). Long term marriage: Age, gender and satisfaction. Psychology \& Aging, 8, 301-303. http://dx.doi.org/10.1037/0882-7974.8.2.301

Lazarus, R. S. (1991). Emotion \& adaptation. New York, NY: Oxford University Press.

Lazarus, R. S., \& Delingis, A. (1983). Psychological Stress and coping in aging. American Psychologist, 38, 245-54. http://dx.doi.org/10.1037/0003-066X.38.3.245 
Leffcourt, H. M. (1976). Locus of control: Current trends in theory and research. New York: Willey.1976.

Marazziti, D. \& Canale, D. (2004). Hormonal changes when falling in love. Psychoneuroendrocrinology, 29 (7) 931-936. http://dx.doi.org/10.1016/j.psyneuen.2003.08.006

Margolin, G. (1980). Behavior exchange in happy and unhappy marriages. A family life cycle perspective. Behavior Therapy, 12,329-343. http://dx.doi.org/10.1016/S0005-7894(81)80122-0

McGrath, E. (1990). Women and depression: Risk factors and treatment issues. Washington DC: American Psychological Association.

Miller, G. A., Galanter, E. \& Pribram, K. H. (1960). Plans and the structure of behavior. New York: Holt, Rinehart \& Wilson. http://dx.doi.org/10.1037/10039-000

Mullen P. E., \& Martin, J. (1994). Jealousy: A community sample. British Journal of Psychiatry, 164, 35-43. http://dx.doi.org/10.1192/bjp.164.1.35

Negi, S. \& Zinta, R. L. (2013). Polyandrous and monogamous lifestyles and wellbeing of people in tribal areas of Kinnaur district of Himachal Pradesh. Journal of Community Guidance \& Research, 30, 2, 151-183.

Parron, E. M. (1982). Golden wedding couples: Lessons in marital longevity. Generations, 7, 14-26.

Parrott, W.G. (1991). The emotional experiences of envy and jealousy. In P. Salovey (Ed.), The psychology of jealousy \& envy (pp. 3-30). New York, NY: Guilford Press

Pfeiffer, S. M., \& Wong, P. T. (1989). Multidimensional jealousy Scale. Journal of Social \& Personal Relationships, 6(2), 181-196. http://dx.doi.org/10.1177/026540758900600203

Rusbult, C. E. (1987). Responses to dissatisfaction in close relationships: The exit-voice loyalty-neglect model. In D. Perlman, \& S. W. Duck (Eds.), Intimate relationships: Development, dynamics, and deterioration (pp. 209-237). Beverly Hills, CA: Sage.

Sarwar, A. (1994). Marital adjustment and depression among working and non-working women. Unpublished M.Phil thesis, National Institute of Psychology, Quaid-i-Azam University, Islamabad.

Sharma, A., \& Zinta, R. L. (2008). Alcoholism: A case study. Indian Journal of Psychology \& Mental Health, 1(2), 195-214. 
Sharpsteen, D. J. (1991). The organization of jealousy knowledge: Romantic jealousy as a blended emotion. In P. Salovey (Ed.), The Psychology of jealousy and envy (pp. 31-51). New York, NY: Guilford Press

Shaver, P. R., Morgan, H. J., \& Wu, S. (1996). Is love a "basic" emotion? Personal Relationships, 3, 81-96. http://dx.doi.org/10.1111/j.1475-6811.1996.tbo0105.x

Simth, H. C. (1961). Personality adjustment. New York: McGraw-Hill. http://dx.doi.org/10.1037/13142-000

Thomas EJ. Marital communication and decision making. New York, Free Press. 1977.

Trawick, M. (1990). Notes on love in a Tamil family. Berkeley, CA: University of California Press.

Veenboven, R. (1983). The growing impact of marriage. Social Indicators Research 1983;12:49-63. http://dx.doi.org/10.1007/BF00428860

Weiten, W. (1986). Psychology applied to modern life. Adjustment in the 80's (2nd edition). California: Words Worth. 1986.

White, G. L., \& Mullen, P. E. (1989). Jealousy: Theory, research, \& clinical strategies. New York, NY: Guilford Press. (Ed.), The psychology of jealousy \& envy (pp. 1-45). New York, NY.

Yum, Y. (2004). Culture and self-construal as predictors of responses to accommodative dilemmas in dating relationships. Journal of Social \& Personal Relationships, 21, 817-835. http://dx.doi.org/10.1177/0265407504047839

Zinta, R. L. \& Negi, S. (2013). Wellbeing: A Case Study on Polyandrous and Monogamous Tribal People. New Delhi: Neha Publications. 